Working Paper 05-66

Economics Series 34

October 2005
Departamento de Economía Universidad Carlos III de Madrid

Calle Madrid, 126

28903 Getafe (Spain)

Fax (34) 916249875

\title{
A SEARCH-THEORETIC MONETARY BUSINESS CYCLE MODEL WITH CAPITAL FORMATION *
}

\author{
Martin Menner ${ }^{1}$
}

\begin{abstract}
Search-theory has become the main paradigm for the micro-foundation of money. But no comprehensive business cycle analysis has been undertaken yet with a search-based monetary model. We extend the model with divisible goods and divisible money of Shi (JET, 1998) to allow for capital formation, analyze the monetary propagation mechanism and contrast the model's implications with US business cycle stylized facts. With empirically plausible adjustment costs the model features a persistent propagation of monetary shocks and is able to replicate fairly well the volatility and cross-correlation with output of key US time series, including sales and inventory investment. We find that monetary policy shocks are unlikely to be an important source of business cycle fluctuations but discover another dimension where money matters: the very frictions that make money essential shape also the responses of variables to real shocks.
\end{abstract}

Keywords: monetary search-theory, business cycles, inventories, capital formation, DSGE model JEL Classification: D83, E19, E32, E49

* I would like to thank especially Hugo Rodriguez, Fabio Canova, Kosuke Aoki, Lawrence Christiano, Ester Faia, Miquel Faig, Jordi Galí, Christian Haefke, Nobuhiro Kiyotaki, Albert Marcet, Michael Reiter, Jaume Ventura, Lutz Weinke and the participants of the CREI Macro Workshop at Universitat Pompeu Fabra, Barcelona for helpful discussions. All remaining errors are mine.

\footnotetext{
${ }^{1}$ Universidad Carlos III de Madrid, C/ Madrid, 12628903 Getafe (Madrid). España. Departamento de Economía. E-mail: mmenner@eco.uc3m.es
} 


\title{
A Search-Theoretic Monetary Business Cycle Model with Capital Formation
}

\author{
Martin Menner $\dagger$ \\ October 2005
}

\begin{abstract}
Search-theory has become the main paradigm for the micro-foundation of money. But no comprehensive business cycle analysis has been undertaken yet with a search-based monetary model. We extend the model with divisible goods and divisible money of Shi (JET, 1998) to allow for capital formation, analyze the monetary propagation mechanism and contrast the model's implications with US business cycle stylized facts. With empirically plausible adjustment costs the model features a persistent propagation of monetary shocks and is able to replicate fairly well the volatility and cross-correlation with output of key US time series, including sales and inventory investment. We find that monetary policy shocks are unlikely to be an important source of business cycle fluctuations but discover another dimension where money matters: the very frictions that make money essential shape also the responses of variables to real shocks.
\end{abstract}

Key words: monetary search-theory, business cycles, inventories, capital formation, DSGE model

JEL Classification: D83, E19, E32, E49

I would like to thank especially Hugo Rodriguez, Fabio Canova, Kosuke Aoki, Lawrence Christiano, Ester Faia, Miquel Faig, Jordi Galí, Christian Haefke, Nobuhiro Kiyotaki, Albert Marcet, Michael Reiter, Jaume Ventura, Lutz Weinke and the participants of the CREI Macro Workshop at Universitat Pompeu Fabra, Barcelona for helpful discussions. All remaining errors are mine. Email: mmenner@eco.uc3m.es

†Universidad Carlos III, Madrid, Spain 


\section{Introduction}

Building on the seminal work of Kiyotaki and Wright [11], [12] search theory has become the main paradigm for the micro-foundation of money. ${ }^{1}$ These models set up an economic environment where money eases bilateral trade in overcoming the problem of an 'absence of double coincidence of wants'. Hence, money plays an essential role in the sense that some of the allocations achievable in a monetary equilibrium cannot be achieved in an equilibrium without money. ${ }^{2}$ Unfortunately, search models create a high degree of heterogeneity of agents: the pairwise exchange of goods generates non-degenerate distributions of goods inventories and money holdings. The use of simulation methods to keep track of these distributions is very cumbersome. Therefore, the early search literature used to make strong assumptions on money holdings in order to limit the state space. ${ }^{3}$ There, an increase in the amount of money increases the proportion of unproductive money holders in the population. Hence, these models are inadequate for monetary business cycle analysis, especially since they inhibit the examination of the effects of a constant rate of money creation and shocks to the money growth rate.

The first successful attempt to overcome the problem of heterogeneity without restrictions on money holdings was presented in Shi [20]. He assumes that the decision making unit - the household - is itself a continuum of agents. Hence, idiosyncratic risk is fully insured and a representative agent formulation can be used. However, the model assumes instantaneous production when a seller is successfully matched with a buyer, and with the absence of final goods inventories an important part of fluctuations in GDP is neglected. $^{4}$ Dropping this latter assumption Shi [21] studies the propagation

\footnotetext{
${ }^{1}$ See for example Rupert et al.[18], chapter 4, for an extensive overview over the literature based on the search-theoretic approach.

${ }^{2}$ Kocherlakota [13] establishes that necessary conditions for the essentiality of money are the lack of complete memory and of full commitment to future actions. The latter follows from the usual assumption of random-matching and rules out the use of credit, while the former inhibits the use of punishments to trigger gift-giving equilibria. See also Corbae, Temzelides and Wright [6] for models with directed search where money remains essential as long as long as agents are restricted to one bilateral trade per period.

${ }^{3}$ The strongest assumption - present in the very first papers of this literature - is that agents can only hold one unit of goods or one unit of money. The following literature relaxed this assumption gradually, but still money holdings have to be either one unit or bounded above by a fixed number.

${ }^{4}$ Recently, Lagos and Wright [14] developed a different modelling device to collapse
} 
of a monetary shock in a search-theoretic monetary model with inventory holdings and labor-search. His analysis reveals the following feedback mechanism that persistently propagates a monetary shock: higher search effort depletes final goods inventories and reduces future goods supply ('inventory effect') which, in turn, induces buyers to keep search intensity high ('searchenhancing effect'). A search friction in the labor market strengthens this feedback and makes the employment response more persistent.

This result, however, needs to be amended with a caveat: the model does not allow for capital formation. A priori, it is not clear whether the introduction of capital formation would not harm the above discussed propagation mechanism, the reason being the following: If households can use part of the acquired goods to increase their capital stock higher sales in the period of the money shock do not necessarily imply a decrease in the supply of goods in subsequent periods. This is because with the increased capital stock there can be produced more goods, and inventories can be filled up more quickly.

The present paper adds endogenous capital formation to the model of Shi [21] to study how the propagation through 'search-enhancing effect', 'inventory effect' and capital formation interact, and how firms use investment in inventories and in fixed capital to deal with variations in demand and supply conditions. This brings the search-theoretic literature closer to modern business cycle models that are based on the neoclassical growth model and adds new dimensions to contrast the model with data: the model eliminates the proportionality of employment and output responses and the identity of consumption and sales, and delivers a series for fixed investment. ${ }^{5}$

the distribution of money holdings. After decentralized trade for specialized goods a centralized market opens where agents trade for a general good in order to adjust their money balances. With quasi-linear preferences in the good traded in the centralized market this implies that all agents end up with the same money holdings. Both approaches have been augmented to allow for capital accumulation (See e.g. Shi [22], [23] and Aruoba and Wright [2]). Faig's [8] solution nests both approaches as special cases in the absence of capital formation. He interprets the continuum of agents not as a household but as a village. Within a village people know each other and their respective trading histories, so insurance contracts among villagers can be used to insure idiosyncratic risk of the agents, and credit is feasible. The introduction of capital formation seems to be more demanding, though. Another drawback shared by both alternatives to Shi's approach is the difficulty to allow for final goods inventories due to unsold goods.

${ }^{5}$ Two related studies also introduce capital into a search-theoretic monetary model. In Shi [22] capital has to be acquired through costly search and saves labor hired in a competitive market. Production is immediate and there are no final goods inventories. Moderate inflation has an extensive effect on the steady state capital stock. Transitional dynamics 
The introduction of capital formation to the search-theoretic model of Shi [21] yields the following results. First, the dynamics of the linearized model with capital formation are explosive. However, the assumption of capital adjustment costs delivers a stable model. Second, with small capital adjustment costs a monetary injection kick-starts higher search intensity, sales, consumption, investment and vacancies. But there is no feedback from inventories since they are filled up to their steady state level within one period. Output and capital peak in the first period and approach rapidly their steady states. Employment shows a less pronounced but still long-lasting response. Third, when a conventional value is assigned to the capital adjustment cost parameter there is a substantial but shorter lasting feedback of the 'search enhancing effect' and the 'inventory effect'. In combination with the propagation through capital formation the employment response to a monetary shock is similar in magnitude and shape to the one obtained in the case of fix capital; the output response reaches its peak earlier. Fourth, eliminating the feedback throug inventories by assuming a very high depreciation rate of inventories the combination of enhanced search-intensity and capital accumulation delivers a negative response of employment to a monetary shock. Therefore, inventories and the search-theoretic feedback keep being necessary to get impulse responses with the correct sign.

When subjected to autoregressive shocks to money growth and to technology the model generates standard deviations relative to output of key macroeconomic variables that are reasonably in line with the corresponding measures in US data. The model is especially succesful in replicating stylized facts of inventories and sales outperforming most of existing DSGE inventory models.

The remainder of this paper is organized as follows: Section 2 describes the model. The role of capital accumulation and inventories for the monetary propagation is discussed in Section 3. Section 4 documents the effects of shocks to monetary policy and technology and compares simulated second moments with those of the corresponding US data. Section 5 concludes.

are not analyzed. Faig [7] constructs a search-theoretic monetary model with neoclassical production where households produce their own capital goods, such that capital has not to be acquired in bilateral exchange and the labor market is Walrasian. In these respects his model is orthogonal to the model presented here. Moreover, he introduces a distinction between producers and sellers, private information about buyers' preferences, and price setting by sellers. This could give rise to a distinct propagation of monetary shocks, but he considers only policies that maintain the nominal interest constant. 


\section{The Model}

\subsection{The Economy with Endogenous Capital Formation}

This section extends Shi's [21] search-theoretic monetary model to allow for capital accumulation. In this model economy there are two search frictions: costly labor search and costly search for consumption goods. The economy is populated by a continuum of households with measure one, denoted by $H$. Each household produces a distinct good with labor and capital as inputs to production. Each good $h \in H$ is storable without modification only by its producer. Each household $h \in H$ produces good $h$ and wants to consume a subset of goods different from its own product. Producers cannot use their own product as capital. This induces a need for exchange before consumption or investment is possible. In the absence of a centralized market with a Walrasian auctioneer households have to search for trading partners with the desired goods. Generally, there will be no double-coincidence of wants. The literature following Kiyotaki and Wright [11], [12] showed that in random search models under certain parametrizations fiat money gets valuable and is the only medium of exchange. To establish this in the present model would require a more detailed consideration of the exchange patterns. Instead, as in Shi [21] fiat money is assumed to be required in each transaction.

The production function is assumed to be neoclassical. The employment of factors of production evolves over time in the following way: A fraction $\delta_{n}$ of the currently employed workers is fired at the end of each period. New workers have to be hired through a costly search process and get productive in the next period. Households invest part of their purchased goods to augment their capital stock in the next period. To do so they have to pay a quadratic installation cost. Each period a fraction $\delta_{k}$ of the capital stock depreciates.

The matching in the goods market between sellers and buyers and in the labor market between producers and unemployed is assumed to be random. Hence, individual agents face idiosyncratic risks: a priori, buyers do not know whether they can find and buy the desired good or whether they have to carry their money home again instead; sellers do not know whether their product will be exchanged for money and whether they will be able to pay their workers, and so on. As a consequence, money holdings, capital stocks and inventories differ across agents, as well as the number of people employed.

To avoid the need of tracking the distributions of money holdings, capital stocks, inventories, and level of employment, it is assumed that the decision 
unit - the household - is itself a continuum of different agents. The members of the household share the bought consumption goods and regard the household's utility as the common objective. Wage payment regardless of whether the firms had a suitable match in the goods market is made possible by resource sharing of firms within a household. Inventory holdings, the capital stock as well as the employees for the next period are shared among the firms of a household, too. Under these assumptions there is no idiosyncratic risk anymore due to the random matching process.

The household consists of five groups: one group of members enjoys leisure while the other four groups are active in markets: Entrepreneurs (set $A_{p}$ with measure $\left.a_{p}\right)$, unemployed $\left(A_{u}\right.$, measure $\left.u\right)$ workers $\left(A_{n t}\right.$, measure $\left.a_{p} n_{t}\right)$, and buyers $\left(A_{b}\right.$, measure $\left.a_{b}\right)$. The values of $a_{p}, u$ and $a_{b}$ are assumed to be constant, while the number of workers per firm $n_{t}$ may vary over time. An entrepreneur consists of two agents: a producer and a seller. A producer in household $h$ hires workers from other households to produce good $h$, which is sold by the seller. A worker inelastically supplies one unit of labor each period to other households' firms. A buyer searches with search intensity $s>0$ to buy the household's desired good. The sellers' search intensity is set to 1. Thus, we focus only on the effect of monetary policy on buyers' search intensity. Let $B=a_{b} / a_{p}$ be the buyers/sellers ratio. In the following a hat on a variable indicates that the household takes this variable and all its future values as given when making the decisions at $t$.

The matching process is specified as follows. The total number of matches in the goods market is given by the matching function:

$$
g(\hat{s}) \equiv z_{1}\left(a_{b} \hat{s}\right)^{\alpha}\left(a_{p}\right)^{1-\alpha}, \quad \alpha \in(0,1) .
$$

By normalizing $z \equiv z_{1} B^{\alpha-1}$ the matching rate per unit of search intensity is $g_{b}(\hat{s}) \equiv z \hat{s}^{\alpha-1}$, so that a buyer finds a desirable seller at a rate $s g_{b}$, and a seller meets a desirable buyer at a rate $g_{s}(\hat{s}) \equiv z B \hat{s}^{\alpha}$. Thus, the measure of the set of buyers with suitable matches, $A_{b^{*}}$, is $s g_{b} a_{b}$ and that of sellers with suitable matches, $A_{p^{*}}$, is $g_{s} a_{p .}{ }^{6}$

Each buyer $j$ having found a seller $-j$ with his desired good exchanges $\hat{m}_{t}(j)$ units of money for $\hat{q}_{t}(-j)$ units of good $-j$, which implies a price of good $-j$ in this match of $\hat{P}_{t}(j)=\hat{m}_{t}(j) / \hat{q}_{t}(-j)$ and an average price of goods of $\hat{P}_{t}{ }^{7}$

\footnotetext{
${ }^{6}$ The notation $*$ stands for agents that are suitably matched in the current period.

${ }^{7}$ The notation $-j$ stands for an agent with whom agent $j$ is matched.
} 
Each producer $j$ can create vacancies $v_{t}(j)$ with a cost of $\Upsilon\left(v_{t}(j)\right)$. Unemployed workers have to search for a job and they do this by supplying one unit of search effort inelastically. A worker supplies inelastically one unit of labor each period and receives a wage $\hat{W}(j)$ in units of money. There is an exogenous constant job separation rate $\delta_{n}$. The matching function in the labor market is linearly homogeneous. The number of matches between firms and unemployed workers is given by $\left(a_{p} \hat{v}\right)^{A}(u)^{1-A}$ and the number of matches per vacancy is $\mu(\hat{v}) \equiv\left(a_{p} \hat{v} / u\right)^{A-1}$.

\subsection{The Households' Decisions}

Households decide at the beginning of each period about their buyers' search intensity $s_{t}$, their consumption $c_{t}$, their total investment $x_{t}$, and the number of vacancies for the firms $v_{t}$. In addition they determine next period's total capital stock $K_{t+1}$, and employment in each of their firms $n_{t+1}$, as well as the amount of 'fiat' money $M_{t+1}$ and inventories $i_{t+1}$ to be carried into period $t+1$. Imposing symmetry within a household each member of a group is assigned the same stocks of capital and money and the same decision rules. Thus, each buyer receives $m_{t+1}=M_{t+1} / a_{b}$ units of money and each firm has a capital stock $k_{t+1}=K_{t+1} / a_{p}$.

The firm's production technology is assumed to be Cobb-Douglas:

$$
f^{i}(n, k)=F_{0} n^{e_{f}} k^{1-e_{f}},
$$

where $e_{f}<1$. For convenience denote $f\left(n_{t}, K_{t}\right) \equiv f^{i}\left(n_{t}, \frac{K_{t}}{a_{p}}\right)$ the individual firm's production function in terms of $K$.

In their decisions households take the sequence of terms of trade and wages $\left\{\hat{q}_{t}, \hat{m}_{t}, \hat{W}_{t}\right\}_{t>0}$ as given, as well as $\left\{M_{0}, K_{0}, i_{0}, n_{0}\right\}$. Since both buyers and sellers have a positive surplus from trade, it is optimal for households to choose $M_{t+1}, K_{t+1}, n_{t+1}$ and $i_{t+1}$ such that in period $t+1$ every buyer carries the required amount of money $\hat{m}_{t+1}$ and that every seller carries $\hat{q}_{t+1}$ units of good $h$. The assumptions $M_{0} \geq \hat{m}_{0} a_{b}$ and $i_{0}+f\left(n_{0}, K_{0}\right) \geq \hat{q}_{0}$ ensure that buyers and sellers do so also in period 0 . 
Households choose the sequence $\Gamma_{h} \equiv\left\{c_{t}, x_{t}, s_{t}, v_{t}, M_{t+1}, K_{t+1}, i_{t+1}, n_{t+1}\right\}_{t \geq 0}$ to maximize their expected lifetime utility over an infinite time horizon:

$$
\max _{\Gamma_{h}} E_{0}\left\{\sum_{t=0}^{\infty} \beta^{t}\left[U\left(c_{t}\right)-\int_{A_{n_{t}}} \varphi d j-\int_{A_{b}} \phi\left(s_{t}(j)\right) d j-\int_{A_{p}} \Upsilon\left(v_{t}(j)\right) d j\right]\right\}
$$

subject to the following constraints:

$$
\begin{aligned}
& c_{t}+x_{t}+\frac{b}{2}\left(\frac{x_{t}}{K_{t}}-\delta_{k}\right)^{2} K_{t} \leq \int_{A_{b t^{*}}} \hat{q}_{t}(-j) d j, \\
& \frac{M_{t+1}}{a_{b}} \geq \hat{m}_{t+1}(j), \quad \forall j \in A_{b t+1^{*}}, \\
& i_{t+1}(j)+f\left(n_{t+1}(j), K_{t+1}\right) \geq \hat{q}_{t+1}(j), \quad \forall j \in A_{p t+1^{*}}, \\
& \left(1-\delta_{k}\right) K_{t}+x_{t} \geq K_{t+1}, \\
& M_{t+1} \leq M_{t}+\tau_{t}-\int_{A_{b t^{*}}} \hat{m}_{t}(j) d j+\int_{A_{n_{t}^{s}}} \hat{P}_{t} \hat{W}_{t}(-j) d j \\
& +\int_{A_{p t^{*}}} \hat{m}_{t}(-j) d j-\hat{P}_{t} \int_{A_{p}} \hat{W}_{t}(j) n_{t}(j) d j \\
& \int_{A_{p}}\left[\left(1-\delta_{n}\right) n_{t}(j)+v_{t}(j) \mu\left(\hat{v}_{t}\right)-n_{t+1}(j)\right] d j \geq 0, \\
& \left(1-\delta_{i}\right)\left[\int_{A_{p}}\left[i_{t}(j)+f\left(n_{t}(j), K_{t}\right)\right] d j-\int_{A_{p t^{*}}} \hat{q}_{t}(j) d j\right] \geq \int_{A_{p}} i_{t+1}(j) d j .
\end{aligned}
$$


Constraint 1 states that the household's consumption and investment plus the quadratic investment cost has to be bought by buyers which successfully meet a trading partner and are endowed with sufficient money for the purchase of $\hat{q}_{t}$ goods each. Condition 2 represents a minimum money holdings constraint for each suitably matched buyer in period $t+1$, while 3 is a similar trading restriction for suitably matched sellers: in period $t+1$ each needs a sufficient stock of inventory and newly produced goods to satisfy the demand of the costumer. Expression 4 is the usual capital accumulation equation. The law of motion of money balances 5 states that money holdings at the beginning of period $t+1$ are no larger than money holdings at the beginning of period $t$ augmented by the monetary injection minus the money spent plus wages earned and cash receipts from firms. Expression 6 indicates that a household cannot allocate more workers of other households to its firms in period $t+1$ than those who worked there in period $t$ and have not quitted plus the newly hired workers. Finally, expression 7 states that inventories in period $t+1$ consist of the fraction of the excess supply of goods in period $t$ which has not depreciated. The quitting rate $\delta_{n}$ and the depreciation rates of inventories, $\delta_{i}$, and capital, $\delta_{k}$, are assumed to be constant.

It is convenient to denote by $\omega_{M t}$ the shadow price of money at the beginning of period $t+1\left(M_{t+1}\right)$, measured in terms of period- $t$ utility. Then $\omega_{M t}$ is the multiplier of 5 . Similarly, let $\omega_{K t}, \omega_{i t}$ and $\omega_{n t}$ be the shadow prices of capital, inventory and workers at the beginning of period $t+1$, all measured in terms of period- $t$ utility. Thus, $\omega_{K t}, \omega_{n t}$ and $\omega_{i t}$ are the multipliers of 4,6 and 7 . Also, let $\Lambda_{t+1}, \omega_{q t+1}$, be the multipliers of equations 2 and 3 , respectively, both measured in terms of period- $t+1$ utility.

\subsection{Terms of Trade}

\subsubsection{Goods Market}

In order to determine the terms of trade in each match and the associated price $P=m / q$, each agent is interpreted as an identity of a small measure $\Delta$. First, the terms of trade contingent on $\Delta$ are calculated, then take the limit $\Delta \rightarrow 0$. This procedure is necessary because the contribution of a match to the households' utility is negligible when agents are negligible in a household. When a seller from household $h$ meets a buyer of household $-h$, they trade $q \Delta$ units of goods against $\bar{m} \Delta$ units of money. These terms of trade lead to 
the following surpluses in the two agents' households: ${ }^{8}$

The seller's surplus: $\quad \omega_{M t} \bar{m}_{t} \Delta-\left[\left(1-\delta_{i}\right) \omega_{i t}+\omega_{q t}\right] q_{t} \Delta$.

The buyer's surplus:

$$
\begin{aligned}
& U\left(\bar{c}_{t}+\zeta q_{t} \Delta\right)-U\left(\bar{c}_{t}\right)+(1-\zeta) q_{t} \Delta \bar{\omega}_{x t} \\
& -\left(\bar{\omega}_{M t}+\bar{\Lambda}_{t}\right) \bar{m}_{t} \Delta,
\end{aligned}
$$

where $\bar{\omega}_{x t}=\omega_{K t} /\left[1+b\left(\frac{x_{t}}{K_{t}}-\delta_{k}\right)\right]=U^{\prime}\left(c_{t}\right)$ is the value of an additional unit of investment and $\zeta$ denotes the fraction of $q_{t}$ which is consumed. Note that the latter equality represents the FOC for $x_{t}$ (see Appendix A.1, equation 16).

Nash-bargaining with equal weights and taking the limit $\Delta \rightarrow 0$ implies:

$$
\begin{aligned}
\omega_{q t} & =\omega_{t}-\left(1-\delta_{i}\right) \omega_{i t}, \\
\bar{\lambda}_{t} & =U^{\prime}\left(\bar{c}_{t}\right)-\bar{\omega}_{t} .
\end{aligned}
$$

with $\bar{\omega}_{t} \equiv P_{t} \bar{\omega}_{M t}$, and $\bar{\lambda}_{t} \equiv P_{t} \bar{\Lambda}_{t}$.

\subsubsection{Wage Bargaining}

The firm's surplus from hiring a new worker is given by:

$\left[\omega_{n t}-\beta\left(1-\delta_{n}\right) \omega_{n t+1}\right] \Delta=\omega_{i t}\left(f\left(n_{t+1}+\Delta, K_{t+1}\right)-f\left(n_{t+1}, K_{t+1}\right)\right)-\beta \omega_{t+1} W_{t+1} \Delta$.

The extra utility for a household when an additional member is working is:

$$
\beta\left(\bar{\omega}_{t+1} W_{t+1}-\varphi\right) \Delta .
$$

The bargaining outcome is the wage rate that maximizes the weighted Nash product of the two agent's surpluses, with weight $\sigma \in(0,1)$. After taking the limit $\Delta \rightarrow 0$, the bargained wage rate is:

$$
W_{t+1}=\sigma \frac{\varphi}{\bar{\omega}_{t+1}}+(1-\sigma) \frac{\omega_{i t} f_{n}\left(n_{t+1}, K_{t+1}\right)}{\beta \omega_{t+1}} .
$$

\footnotetext{
${ }^{8}$ Symbols with a bar refer to variables of household $-h$.
} 


\subsection{Equilibrium}

DEFINITION: A symmetric search equilibrium is a sequence of household's choices $\Gamma_{h} \equiv\left\{\Gamma_{h t}\right\}_{t>0}, \Gamma_{h t} \equiv\left(c_{t}, x_{t}, s_{t}, v_{t}, M_{t+1}, i_{t+1}, n_{t+1}, K_{t+1}\right)$, expected quantities in trade $\hat{X} \equiv\left\{\hat{X}_{t}\right\}_{t>0}, \hat{X}_{t} \equiv\left(\hat{m}_{t}, \hat{q}_{t}, \hat{W}_{t}\right)$, terms of trade $\left\{X_{t}\right\}_{t \geq 0}$ and expected average variables $\hat{s} \equiv\left\{\hat{s}_{t}\right\}_{t \geq 0}, \hat{v} \equiv\left\{\hat{v}_{t}\right\}_{t \geq 0}$, such that

(i) all variables are identical across households and relevant individuals;

(ii) given $\hat{X}$ and $\left(M_{0}, i_{0}, n_{0}, K_{0}\right), \Gamma_{h}$ solves $(\mathrm{PH})$ with $(s, v)=(\hat{s}, \hat{v})$;

(iii) $X_{t}$ satisfies 8,9 and 10 ;

(iv) $\hat{X}_{t}=X_{t} \quad \forall t \geq 0$.

This implies that households take the sequence $\hat{X}$ as given when choosing $\Gamma_{h}$.

The equations determining equilibrium are derived in Appendix A.1.

\section{Monetary Propagation}

The dynamics of this model cannot be examined analytically, so the model is calibrated and the log-linearized dynamic system is solved by standard techniques. ${ }^{9}$ Unless specified otherwise parameter values proposed by Shi [21] are used for reasons of comparability. For the capital depreciation rate assume a value of $2.5 \%$ per quarter. The calibration procedure is shown in Appendix A.2, and Table 1 shows the chosen parameter values. Without any capital adjustment cost the model gets unstable, but with a value for the adjustment cost parameter $b$ larger than 6 one obtains stable eigenvalues of the dynamic system and reasonable impulse responses. Since the usual values of $b$ in the literature are at least 3 times as high one can be quite comfortable with the stability properties of the model and hence further discussion will be restricted to the cases where $b \geq 6 .^{10}$

\footnotetext{
${ }^{9}$ Here the 'Toolkit for analyzing nonlinear dynamic stochastic systems easily' of Uhlig $[24]$ is used.

${ }^{10}$ This feature of unstability in the absence of capital adjustment costs is not shared by other equilibrium business cycle models with capital. However, adjustment costs were recently incorporated in those models in order to solve the problem of excess volatility in investment usually found there. See Neiss and Pappa [17] for a discussion.
} 


\subsection{Dynamics with Constant Capital}

The solution of the model presented here allows to study how capital accumulation alters the dynamics of the search-theoretic monetary model of Shi [21]. In order to ease the comparison between the two models it is convenient to first describe the monetary propagation through the 'inventory effect' of the model with constant capital.

In Shi's [21] model a positive shock to the growth rate of money reduces the shadow value of money. The implied fall in the value of wages and sales leads to a reduction in labor supply and labor demand and, hence, in employment and output. In addition to this conventional 'inflation effect' there is a 'search-enhancing effect' which more than offsets the negative effect on employment and output: search gets more profitable when the value of holding money falls since a higher search intensity increases the probability of a suitable match where the now less valuable money can be exchanged for a consumption good. Hence, buyers spend more shoe-leather to get rid of the less valuable money, and less unsold goods remain as inventories for next period. This 'inventory effect' in turn reinforces the 'search-enhancing effect': facing a reduced supply of goods buyers search more intensively in the subsequent period, too. The interplay of these two effects creates a feedback mechanism that increases sales revenues in subsequent periods which leads to a higher demand for labor that persist over various periods.

\subsection{Dynamics in the Presence of Capital Accumulation}

To see how the existence of capital changes this mechanism it is useful to look at the impulse responses after a monetary shock. Figure 1 shows the reaction of some key variables of the model economy after a one-standard deviation shock to money growth with three levels of adjustment costs for capital: $b=\{6,17.8,10000\}$. The value $b=6$ (dash-dotted lines) is the lowest one that results in non-zig-zagged impulse responses, $b=17.8$ corresponds to the benchmark case of medium capital adjustment costs, and the case $b=10000$ (solid lines) corresponds to the model with constant capital as developed in Shi [21]. Note, that households choose to increase consumption by $0.5 \%$ independent of the capital adjustment cost. The lower $b$, the stronger the investment response to a monetary shock and the more search-intensity has to increase in order to acquire these investment goods. 
Let's first compare the benchmark case of medium adjustment costs with the case of constant capital. In Figures $1 \mathrm{a}-1 \mathrm{~h}$ the bold responses with benchmark adjustment costs are very similar in shape to the solid ones with fix capital, but show a little less persistence. This indicates that with a medium adjustment cost the feedback between 'search-enhancing effect' and 'inventory effect' is only slightly modified by the introduction of capital accumulation. Figures $1 \mathrm{j}$ and $1 \mathrm{k}$ present the responses of the two variables that do not appear in a model with constant capital: investment increases since the household has a consumption smoothing motive due to its concave utility; and the higher investment raises next period's capital stock.

Now, production and employment are no longer proportional as reflected in Figures $1 \mathrm{~h}$ and $1 \mathrm{~m}$. Employment keeps adjusting slowly due to the search friction in the labor market. Output, however, peaks earlier and stronger due to the increased capital stock. Inventories can be filled up more quickly, and the supply gap is closed about 2 quarters earlier in the case of moderate adjustment costs. So, buyers do not keep search effort high for many periods, as can be seen in Figures 1e and 1d.

Hence, the feedback mechanism between the 'search-enhancing' effect and the 'inventory effect' is weaker, and the search-intensity approaches its steady state value earlier. But there is some persistence in the propagation of the monetary shock due to capital accumulation: Figures $1 \mathrm{c}$ and $1 \mathrm{j}$ show that one period after the money shock sales and investment fall below their steady state value. In the presence of capital adjustment costs the disinvestment process is smoothed over time and hence capital decreases only slowly; output stays persistently above steady state.

Results change significantly when firms can adjust their capital stock more quickly since they face lower capital adjustment costs. Consider dash-dotted impulse responses in Figure 1. Investment and capital react strongly to the increase in the purchases of the household's favorable goods. Therefore, with the better production possibilities inventories are filled up within 2 periods. So, there is no persisting excess demand in the goods market and hence no reason for the search intensity to stay above steady state in the subsequent periods. Thus, the 'inventory effect' breaks down and with it the searchtheoretic feedback mechanism. Nevertheless the impact on search intensity is higher in the first period since the shadow value of money drops by more. The former even drops below steady state in the second period, since the shadow value of money jumps substantially above steady state. This, in turn, is caused by the fact that the goods supply drops drastically in the second 
period. As can be seen in Figure 1k the capital stock quickly decreases after the peak, so there is nearly no 'capital accumulation effect'. The persistence in output (Figure 1m) is mainly the result of the labor search friction.

Summarizing, we can see that a substantial temporary increase in fixed capital in the case of low adjustment costs eliminates rapidly the excess demand caused by the inventory disinvestment after a monetary shock. Once the supply gap is filled, the excess capital is disinvested rapidly, too. By contrast, with moderate adjustment costs the smoother increase in capital investment reduces the time till this excess demand is eliminated only slightly. There is still a substantial feedback between search-intensity and inventories. Capital is not disinvested that quickly, either, and thus helps propagating the monetary shock. The combined effect leads to employment and output responses similar to the case of constant capital.

\subsection{The Role of Inventories}

This subsection addresses the question whether inventories continue to play a crucial role in the presence of capital accumulation. Figure 2 shows the impulse responses for a moderate capital adjustment cost and a depreciation rate of inventories of 0.95 . That means that unsold goods can be stored to the next period only under large losses. Only $5 \%$ of unsold goods survive as inventories for the beginning of next period. So, inventories only play a minor role as a storage technology, and the goods supply is mainly determined by current production. As can be seen in Figures $2 \mathrm{~b}, 2 \mathrm{~d}$ and $2 \mathrm{e}$ the propagation through 'search enhancing effect' and 'inventory effect' becomes insignificant. Inventories change little and are back to steady state very quickly. Thus, there is no reduction in goods supply in subsequent periods.

On the contrary, the higher stock of capital, which was built up to smooth consumption after the monetary shock, allows to produce more efficiently, thereby increasing the goods supply. Consequently, buyers don't have to search harder in subsequent periods, either, and search effort approaches its steady state after 2 periods. As shown in Figures $2 \mathrm{c}$ and $2 \mathrm{f}$, sales and sales revenues are back to steady state after 2 periods, too. Because sales revenues don't remain above steady state there are no higher profits to be made in the future and firms are not induced to hire more workers. Figure $2 \mathrm{i}$ shows that consumption remains slightly above steady state, so households do not need to disinvest in order to smooth consumption. Therefore, the capital stock decreases only by depreciation, as seen in Figure 2k. Figures $2 \mathrm{e}$ and $2 \mathrm{~m}$ 
show that goods supply and output stay persistently above steady state even though employment (Figure $2 \mathrm{~h}$ ) decreases due to the substitution by capital. That means that some propagation still takes place through the channel of capital accumulation. ${ }^{11}$ But the output response is much smaller than in the benchmark model. Moreover, there is a switch in sign in the employment response which is at odds with empirical evidence. Hence, the possibility to store goods in inventories remains a crucial element of the search-theoretic monetary model, even in the presence of capital accumulation.

\section{Effects of Monetary Policy and Technology Shocks}

Up to now we studied the reaction of our model economy to an impulse shock to the growth rate of money in order to analyze the monetary propagation mechanism through search-frictions, inventory holdings and capital accumulation. In this section the model economy is subjected to two types of shocks that presumably perturb real world economies: a monetary policy (MP) shock and a technology shock. This enables us to compare the responses of the model with 'stylized facts' extracted from the data.

Note, that the empirical literature identifies a monetary policy shock as a linear combination of reduced form innovations in a vector autoregression, rather than as an innovation in money growth ${ }^{12}$. To make use of the results of this empirical literature the stochastic process of the growth rate of money is specified such that it mimics the one of the growth rate of M1 implied by an identified monetary policy shock. This strategy is taken from Christiano, Eichenbaum and Evans [4] (CEE). They estimate a VAR with output, prices, a commodity price index, the federal funds (FF) rate, non-borrowed reserves, total reserves and a monetary aggregate. The response of the monetary aggregate to a monetary policy shock as measured by the innovations in the federal funds rate characterizes the changes in money that are associated with the changes in the interest rate. Thus, equivalently, one can think about the implied response of the monetary aggregate as being the cause (the MP

\footnotetext{
${ }^{11}$ Again, this depends to a large amount on the size of the adjustment cost. The higher the adjustment cost the longer is the propagation of a monetary shock.

${ }^{12}$ See, e.g. Christiano et al. [5] for the implications of different identification schemes for empirical impulse response functions after a MP shock.
} 
shock) and the interest rate response being the effect. Let's call the impulse response of M1 after a monetary policy shock a 'CEE MP shock in M1', and the innovation in the FF rate a 'CEE MP shock in FF'. All other variables in the VAR react indistinguishably to these two kinds of shocks. Feeding the model with the implied money growth response series is hence equivalent to feed the model with an identified MP shock series.

Under the hypothesis that the response of money growth to a CEE MP shock in $\mathrm{FF}$ follows an $\mathrm{AR}(1)$ process with autoregressive parameter $\rho$, one can test if a specific $\rho$ is consistent with the null hypothesis. Following this approach using monthly data the $\rho$ with the highest p-value is selected. This leads to a value of $\rho=0.55$ and a standard deviation of the money growth series of $\sigma_{g}=0.004716$. The monetary injection in the model economy is now assumed to take place at the beginning of the period. This timing is more in line with other business cycle models. The production function can be expressed as $f\left(n_{t}, K_{t}\right)=\Psi_{t} F_{0} n_{t}^{e_{f}} K_{t}^{1-e_{f}}$, where $\Psi_{t}$ is the stochastic level of technology assumed to follow an $\operatorname{AR}(1)$ process:

$$
\log \left(\Psi_{t}\right)=\rho_{\Psi} \log \left(\Psi_{t-1}\right)+\varepsilon_{\Psi t},
$$

with $\rho_{\Psi}=0.979$ and standard deviation $\sigma_{\Psi}=0.00712$ as usually done in the real business cycle literature. All other model parameters are calibrated as before. Finally, it should be noted that the following results are contingent on the specific calibration of model parameters.

\subsection{Impulse Responses}

Figure 3 shows the impulse responses of the model economy hit by a CEE MP shock in M1 compared to the benchmark case of an impulse shock as in the previous section. The impulse responses are generally smoother in the case of the MP shock. The employment and output reactions approach their peaks about 2 periods later which is more in line with responses found in the data, but the magnitudes are still too small. A different set of plausible parameter values might bring the responses closer to the one of the data. For example, reducing hiring costs increases the magnitude of employment and output responses. In the next section I discuss also the implication of lower hiring costs for second moments of simulated data. Apart from that, however, no further attempt to improve the calibration in these respects is pursued in this paper. Instead, it is planned for future work to assess the capability of the model to match the data using estimated model parameters. 
Figure 4 shows the impulse responses of the model economy hit by technology shocks. A positive technology shock increases current output, goods supply and sales. Higher sales lead to higher investment in order to smooth consumption. This increases capital. In subsequent periods output is increased by the lasting technology shock and by the higher stock of capital so that employment has to decrease strongly in order to bring output back to steady state. Hence we see a clear substitution effect between employment and capital. This decrease in employment is optimal for firms since disinflation depresses future sales revenues and the incentives to hire workers. The disinflation comes from the fact that a higher goods supply due to the technology shock reduces search intensity and thus the shadow value of money. The reduced search intensity reduces the probability of trade matches leaving more leftovers to be stored as inventories.

In other words, in addition to capital investment households make use of inventory investment as intertemporal storage device. Inventories allow to pile up goods produced with good technology that can be consumed later. In the absence of final good inventories as a storage device (case $\delta_{i}=0.95$ ) households would be obliged to invest a higher quantity in fixed capital in order to smooth consumption and firms could not reduce their workforce that much because they face a higher demand for investment purposes. Output stays higher in comparison to the benchmark case with inventories.

This means that the search friction in the goods market alters the magnitude of the dynamic responses of output, employment and capital to a technology shock, and it induces hump-shapes in the responses of investment, consumption and sales. Finally, a striking feature is that the negative inflation response is highly persistent although prices are perfectly flexible.

\subsection{Volatility}

Actual and simulated standard deviations presented in Table 2 indicate how well the model variables match the volatility of their empirical US counterparts. Simulation results are shown for the cases with technology shocks being the only shocks hitting the economy, second, with monetary policy and technology shocks, and third with both shocks assuming lower hiring costs. As can be seen in column 5 in the case of technology shocks the volatilities of the simulated series fall reasonably well within the range of documented volatilities. The variation of consumption, investment and capital, are quite near to observed values. Employment and vacancies vary significantly less 
than in the data. These results do not change substantially when we add monetary shocks as shown in column 6 . However, the low variability of labor market variables is partly overcome by lowering hiring costs to a tenth of the calibrated value, as seen in column 7 . In all the three cases sales are less volatile than output and match the data very well. This feature is hard to find in monetary DSGE models of inventory holdings ${ }^{13}$. Note, that a supply (demand) shock leads to investment (disinvestment) of inventories, letting sales increase less (more) than output ${ }^{14}$. Since supply shocks are calibrated to be more volatile than demand shocks the effect of the former dominates. In addition, monetary shocks increase substantially the volatilities of sales, inventory investment and the inventory to sales ratio and drive them away from their empirical counterparts. Therefore, the present model - contingent on the chosen calibration - would imply that monetary shocks cannot be an important source of economic fluctuations at business cycle frequencies.

\subsection{Comovement and Autocorrelation}

Table 3 documents the contemporary correlations of US time series for consumption, investment, employment, final sales, inventory investment, the inventories-sales ratio with output, and of the latter two variables with sales, together with the corresponding ones generated from the model. In all of the simulation scenarios the model performs considerably well in replicating the correlations of consumption, investment, final sales and inventory investment with output. The search-theoretic monetary model treats inventories as a buffer stock to accommodate for variations in sales. Nevertheless it does not share with other "buffer stock" and "production smoothing" models the problem that they cannot account for another important stylized fact with respect to inventories, that sales and inventory investment are positively correlated over the business cycle. However, in the presence of monetary shocks the model fails to replicate this positive correlation between inventory investment and sales. This is another hint, that according to the model monetary

\footnotetext{
${ }^{13}$ Boileau and Letendre [3] compare 3 different types of models: A production smoothing model with stockout costs, a model with inventories as input in production, and a shopping cost model. None of them can reproduce a lower volatility of sales relative to output and a significantly positive correlation between inventories and output. The searchtheoretic model shares with the ones considered there the problem of a too large volatility of inventory investment.

${ }^{14}$ Remember that GDP=Sales+Inventory Investment.
} 
shocks cannot be a dominant source of business cycle fluctuations. The negative correlation of the inventories-sales ratio with output and sales cannot be accounted for in a significant way ${ }^{15}$. Independently of the shocks considered the model produces acyclical rather than procyclical employment responses.

Finally, the model reasonably reproduces the autocorrelation of output and sales, as can be seen in Table 4. The first three autocorrelations of output and sales are quite close to the sample counterparts documented by Hornstein-Sarte [9]. Here, the scenario with both shocks gets substantially closer to the values in the data than the one with technology shocks only.

\section{Conclusion}

The introduction of capital accumulation into a search-theoretic monetary model allowed us to study the interaction of search-intensity, inventory investment and capital formation in the propagation of monetary shocks. In the absence of capital adjustment costs the search-inventory feedback mechanism documented in Shi [21] vanishes. However, with moderate capital adjustment costs the combination of this mechanisms with a propagation through capital formation results in an employment response similar to the one with constant capital. Moreover, final good inventories and the search-inventory feedback are crucial to get the correct positive sign of the employment response after a monetary shock and to generate hump-shaped responses of inventories, sales and consumption, and a persistent inflation response after a technology shock.

With the introduction of capital accumulation this model economy is rich enough to make predictions about many variables of interest in business cycle analysis: in contrast with the basic model one obtains simulated time series for consumption, investment, output and the capital stock. Hence, we are able to study how good a model based on costly exchange in goods markets can replicate business cycle stylized facts. The main findings of our informal comparison of the second moments with the ones implied by US data are: First, the model matches the relative volatility of most US key business cycle variables, only labor and vacancies vary too little. Second, the model generates more variability in output than in sales - a feature of the

\footnotetext{
${ }^{15}$ To our knowledge the (S,s)-type model in Khan and Thomas [10] is the only (nonmonetary) DSGE model that can reproduce all the inventory facts documented in Table 2 to Table 4 . To get these results they assume the dominance of supply shocks.
} 
data that DSGE inventory models with the exception of (S,s)-type models cannot match. However, as in most competitor models, inventory investment is too volatile. Third, in contrast to other inventory models that also treat inventories as a "buffer stock" against demand shocks, the present model can replicate the stylized fact that inventory investment is positively correlated to sales. However the model fails to replicate the negative correlation of the inventory/sales ratio with sales. Fourth, with respect to inventories and sales the model matches almost all stylized facts - outperforming all other inventory models but the (S,s)-type model. It can be considered as a model that treats inventory investment in a tractable and plausible way.

The explicit modelling of money as a means of transactions in bilateral exchange did not lead to the conclusion that monetary policy is of great importance as a source of business cycle fluctuations. This might not be surprising in a model where wages and prices are flexible. But the interplay between search intensity and inventories modifies also the propagation of technology shocks, and this helps to replicate the stylized facts of inventory investment and sales. Hence we find that money matters in a different direction: the very frictions that make money essential also shape the responses of model variables to real shocks.

Obviously, the reported impulse responses and second moments are contingent on the chosen parameter values. Further steps in the empirical evaluation of the model might be the comparison of the impulse responses of the model economy to a monetary shock with the ones obtained by a structural VAR estimation. Such exercises have been conducted so far only with Walrasian monetary business cycle models. ${ }^{16}$ Alternatively, a Bayesian approach could be used to assess the model's ability to track empirical time series, their second moments or empirical impulse response functions using the posterior estimates of the parameters and contrast it with the performance of VAR's or other dynamic stochastic general equilibrium (DSGE) models ${ }^{17}$. Finding out in which dimensions the search-theoretic model does better or worse than more standard ones might then serve as a guidance how to improve the model.

\footnotetext{
${ }^{16}$ See Nason and Cogley [16] for an example.

${ }^{17}$ See Schorfheide [19] for a Bayesian approach using loss functions to compare empirical and theoretical models in these dimensions.
} 


\section{References}

[1] D. Andolfatto. Business cycles and labor-market search. American Economic Review 86, pages 112-132, 1996.

[2] S. B. Aruoba and R. D. Wright. Search, money and capital: A neoclassical dichotomy. PIER Working Paper No. 02-036, September 9, 2002.

[3] M. Boileau and M.-A. Letendre. Inventories, sticky prices and the propagation of nominal shocks. Department of Economics Working Papers 2004-03, McMaster University, (2004-03), Mar. 2004. available at http://ideas.repec.org/p/mcm/deptwp/2004-03.html.

[4] L. J. Christiano, M. Eichenbaum, and C. L. Evans. Modelling money. NBER Working Paper No. 6371, 1998.

[5] L. J. Christiano, M. Eichenbaum, and C. L. Evans. Monetary policy shocks: What have we learned and to what end? Handbook of Macroeconomics, ed. J.B. Taylor and M. Woodford, Elsevier, North Holland, 1999.

[6] D. Corbae, T. Temzelides, and R. Wright. Matching and money. American Economic Review Papers and Proceedings 92, pages 67-71, 2002.

[7] M. Faig. A search theory of money and commerce with neoclassical production. Manuscript, pages 43, 2002.

[8] M. Faig. Divisible money in an economy with villages. Econometric Society 2004 North American Summer Meetings, (248), Aug 2004. available at http://ideas.repec.org/p/ecm/nasm04/248.html.

[9] A. Hornstein and P.-D. Sarte. Staggered prices and inventories: Production smoothing reconsidered. FRB of Richmond Working Paper 98-8, pages 1-27, 1998.

[10] A. Khan and J. K. Thomas. Inventories and the business cycle: An equilibrium analysis of (S,s) policies. Manuscript, pages 40, 2004.

[11] N. Kiyotaki and R. Wright. A contribution to the pure theory of money. Journal of Economic Theory 53, pages 215-253, 1991. 
[12] N. Kiyotaki and R. Wright. A search-theoretic approach to monetary economics. American Economic Review 83, pages 63-77, 1993.

[13] N. Kocherlakota. Money is memory. Journal of Economic Theory 81, pages 231-50, 1998.

[14] R. Lagos and R. Wright. A Unified Framework for Monetary Theory and Policy Analysis. Journal of Political Economy, volume 113, pages 463-484, 2002.

[15] M. Merz. Search in the labor market and the real business cycle. Journal of Monetary Economics 36(2), pages 269-300, 1995.

[16] J. M. Nason and T. Cogley. Testing the implications of long-run neutrality for monetary business cycle models. Journal of Applied Econometrics 9, pages S37-S70, 1994.

[17] K. S. Neiss and E. Pappa. A monetary model of factor utilisation. Bank of England Working Paper Series 154, 2002.

[18] P. Rupert, M. Schindler, A. Shevchenko, and R. Wright. The searchtheoretic approach to monetary economics: A primer. Federal Reserve Bank of Cleveland: Economic Review, pages 10-28, 2000.

[19] F. Schorfheide. Loss function-based evaluation of DSGE models. Journal of Applied Econometrics, 15(6):645-670, 2000.

[20] S. Shi. A divisible search model of fiat money. Econometrica, 65(1):75102, 1997.

[21] S. Shi. Search for a monetary propagation mechanism. Journal of Economic Theory 81, pages 313-357, 1998.

[22] S. Shi. Search, inflation, and capital accumulation. Journal of Monetary Economy 44(1), pages 81-103, 1999.

[23] S. Shi. Liquidity, bargaining, and multiple equilibria in a search monetary model. Annals of Economics and Finance, 2:191-217, 2001.

[24] H. Uhlig. A toolkit for analyzing nonlinear dynamic stochastic models easily. Electronic: http:// www.wiwi.hu-berlin.de/wpol/html/toolkit.htm, 1997. 


\section{Appendix}

\section{A.1 Equilibrium Conditions}

Necessary conditions for an optimum are the FOCs (with respect to $M_{t+1}$, $i_{t+1}, n_{t+1}, K_{t+1}, s_{t}, x_{t}$, and $\left.v_{t}\right)$ :

$$
\begin{gathered}
\omega_{M t}=\beta E_{t}\left\{\omega_{M t+1}+g_{b}\left(\hat{s}_{t+1}\right) s_{t+1} \Lambda_{t+1}\right\}, \\
\omega_{i t}=\beta E_{t}\left\{g_{s}\left(\hat{s}_{t+1}\right) \omega_{q t+1}+\left(1-\delta_{i}\right) \omega_{i t+1}\right\}, \\
\omega_{n t}=E_{t}\left\{\beta\left(1-\delta_{n}\right) \omega_{n t+1}-\beta \omega_{M t+1} \hat{P}_{t+1} \hat{W}_{t+1}+\omega_{i t} f_{n}\left(n_{t+1}, K_{t+1}\right)\right\}, \\
\omega_{K t}=E_{t}\left\{\beta\left(1-\delta_{k}\right) \omega_{K t+1}+\beta U^{\prime}\left(c_{t+1}\right) \frac{b}{2}\left(\left(\frac{x_{t+1}}{K_{t+1}}\right)^{2}-\delta_{k}^{2}\right)\right. \\
\left.+a_{p} \omega_{i t} f_{k}\left(n_{t+1}, K_{t+1}\right)\right\}, \\
\Phi^{\prime}\left(s_{t}\right)=g_{b}\left(\hat{s}_{t}\right)\left[U^{\prime}\left(c_{t}\right) \hat{q}_{t}-\omega_{M t} \hat{m}_{t}\right], \\
U^{\prime}\left(c_{t}\right)\left[1+b\left(\frac{x_{t}}{K_{t}}-\delta_{k}\right)\right]=\omega_{K t}, \\
\omega_{n t}=\Upsilon^{\prime}(v) / \mu,
\end{gathered}
$$

with the slackness conditions associated with 2 and 3 :

$$
\begin{gathered}
\Lambda_{t+1}\left[\frac{M_{t+1}}{a_{b}}-\hat{m}_{t+1}\right]=0, \quad \forall j \in A_{b t+1^{*}}, \\
\omega_{q t}\left[i_{t+1}+f\left(n_{t+1}, K_{t+2}\right)-\hat{q}_{t+1}\right]=0, \quad \forall j \in A_{p t+1^{*}},
\end{gathered}
$$

and the transversality equation:

$$
\lim _{t \rightarrow \infty} \beta^{-t} E_{t}\left\{\omega_{K t} K_{t}\right\}=0 .
$$

These optimality conditions together with the laws of motion for capital, money balances, employment and inventories $4-7$, the resource constraint 1 and the trading constraints 2 and 3 determine the solution to this decision problem once the terms of trade are specified, i.e. equations 8,9 and 10 hold, and the equilibrium conditions are imposed. 
Considering symmetric equilibria, hats on aggregate variables and bars on household specific variables can be suppressed. As in Shi [21] attention will be restricted to the case where $\lambda>0$ and $\omega_{q}>0$. It can be shown that around the steady state the requirements for $\lambda$ and $\omega_{q}$ being positive are fulfilled. It is now possible to reduce the system of equations defining this equilibrium.

First, the price level is $P_{t}=m_{t} / q_{t}=M_{t} /\left(a_{b} q_{t}\right)$. Because of symmetry equation 5 reduces to $M_{t+1}=M_{t}+\tau_{t}$. Define the gross rate of money growth between periods $t$ and $t+1$ as $\gamma_{t} \equiv M_{t+1} / M_{t}$. Thus, $\tau_{t}=\left(\gamma_{t}-1\right) M_{t}$, and the gross inflation rate between periods $t$ and $t+1$ is given by $P_{t+1} / P_{t}=\gamma_{t} q_{t} / q_{t+1}$.

Some static inequalities can be simplified as follows: Under symmetry $\mu$ is a function of $v$ and one can define $k(v) \equiv \Upsilon^{\prime}(v) / \mu(v)$. Thus, equality 17 reads $\omega_{n}=k(v)$. When $\lambda>0$, expression 1 becomes $c_{t}=a_{p} B z s_{t}^{\alpha} q_{t}-$ $x_{t}-\frac{b}{2}\left(\frac{x_{t}}{K_{t}}-\delta_{k}\right)^{2} K_{t}$, and with $\omega_{q}>0$, expression 3 reads $q=i+f(n, K)$. After substituting the expression for $g_{b}$ expression 14 becomes $s_{t}^{1-\alpha} \Phi^{\prime}\left(s_{t}\right)=$ $z q_{t}\left(U^{\prime}\left(c_{t}\right)-\omega_{t}\right)$.

Using the bargaining solution we can eliminate $\omega_{q}, \lambda$, and $W$ : The multiplier $\omega_{q}$ can be replaced by $\omega-\left(1-\delta_{i}\right) \omega_{i}$ through 8 , with $9 \lambda$ can be eliminated, and the wage rate $W$ is given by 10 .

To simplify further one can express the dynamic equilibrium conditions in terms of $\left(n, i, K, \omega, v, \omega_{i}, \omega_{k}\right)$ by elimination of $\omega_{n}$ and $m$ : The multiplier $\omega_{n}$ can be replaced by $k(v)$ using expression 17 , and by definition $m=P q$.

This leads to a system of static equations:

$$
\begin{gathered}
k\left(v_{t}\right)=\Upsilon^{\prime}\left(v_{t}\right) / \mu\left(v_{t}\right), \\
q_{t}=i_{t}+f\left(n_{t}, K_{t}\right), \\
c_{t}=a_{p} B z s_{t}^{\alpha} q_{t}-x_{t}-\frac{b}{2}\left(\frac{x_{t}}{K_{t}}-\delta_{k}\right)^{2} K_{t}, \\
U^{\prime}\left(c_{t}\right)\left(1+b\left(\frac{x_{t}}{K_{t}}-\delta_{k}\right)\right)=\omega_{K t}, \\
s_{t}^{1-\alpha} \Phi^{\prime}\left(s_{t}\right)=z q_{t}\left[U^{\prime}\left(c_{t}\right)-\omega_{t}\right],
\end{gathered}
$$

where 21 is a convenient definition and the other equations jointly determine $\left\{q_{t}, c_{t}, x_{t}, s_{t}\right\}$ as functions of the states $\left\{n_{t}, i_{t}, K_{t}\right\}$ and the costates $\left\{\omega_{t}, \omega_{K t}\right\}$. 
Substituting above expressions into 6 - 15 one gets the dynamic system:

$$
\begin{gathered}
n_{t+1}=\left(1-\delta_{n}\right) n_{t}+v_{t} \mu_{t}(v), \\
i_{t+1}=\left(1-\delta_{i}\right)\left(i_{t}+f\left(n_{t}, K_{t}\right)-B z s_{t}^{\alpha} q_{t}\right), \\
K_{t+1}=\left(1-\delta_{k}\right) K_{t}+a_{p} B z s_{t}^{\alpha} q_{t}-c_{t}-\frac{b}{2}\left(\frac{x_{t}}{K_{t}}-\delta_{k}\right)^{2} K_{t}, \\
\omega_{t}=\beta E\left\{\frac{q_{t+1}}{\gamma_{t} q_{t}}\left(\omega_{t+1}+z s_{t+1}^{\alpha}\left[U^{\prime}\left(c_{t+1}\right)-\omega_{t+1}\right]\right)\right\}, \\
k\left(v_{t}\right)=E\left\{\beta\left(1-\delta_{n}\right) k\left(v_{t+1}\right)+\sigma\left[\omega_{i t} f_{n}\left(n_{t+1}, K_{t+1}\right)-\beta \varphi\right]\right\}, \\
\omega_{i t}=\beta E\left\{\left(1-\delta_{i}\right) \omega_{i t+1}+B z s_{t}^{\alpha}\left(\omega_{t+1}-\left(1-\delta_{i}\right) \omega_{i t+1}\right)\right\}, \\
\omega_{K t}=E\left\{\beta\left[\left(1-\delta_{k}\right) \omega_{K t+1}+\frac{b}{2}\left(\left(\frac{x_{t+1}}{K_{t+1}}\right)^{2}-\delta_{k}^{2}\right) U^{\prime}\left(c_{t+1}\right)\right]\right. \\
\left.+a_{p} \omega_{i t} f_{k}\left(n_{t+1}, K_{t+1}\right)\right\},
\end{gathered}
$$

where 26 - 28 are the laws of motion of the state variables $\left\{n_{t}, i_{t}, K_{t}\right\}$ and the others are expectational equations for the jump variables $\left\{\omega_{t}, v_{t}, \omega_{i t}, \omega_{K t}\right\}$.

\section{A.2 Calibration}

For sake of comparability the values of all parameters that were exogenously specified by Shi [21] are kept the same and shown in the 2 first rows of Table 1 . The last row is calibrated in the following way:

As in Shi [21], the disutilities of search and vacancies are assumed to be:

$$
\phi(s)=\varphi\left(\varphi_{0} s\right)^{1+1 / e_{\phi}}, \quad \Upsilon(v)=\Upsilon_{0} v^{2} .
$$

Further, assume that the production function has the form:

$$
f(n, K)=F_{0} n^{e_{f}}\left(\frac{K}{a_{p}}\right)^{1-e_{f}} .
$$

Total factor productivity is normalized to one: $F_{0}=1$. Define $F=\frac{1}{a_{p}^{1-e_{f}}}$ to express production per firm as $f(n, K)=F n^{e_{f}} K^{1-e_{f}}$.

The capital depreciation rate $\delta_{k}$ is assumed to be $2.5 \%$ quarterly. The adjustment cost parameter $b$ is calibrated such that the semi-elasticity of investment with respect to real asset returns (Tobin's Q) is $2.25 .^{18}$ If $\Phi(I / K)$

\footnotetext{
${ }^{18}$ See Neiss and Pappa [17].
} 
denotes the adjustment cost function, then $Q \equiv 1 / \Phi^{\prime}(I / K)$ can be interpreted as Tobin's Q:

$$
\left(s e m i \_\varepsilon\right)_{I Q}=-\frac{\delta Q \cdot I}{\delta I}=\frac{\Phi^{\prime \prime}}{\left(\Phi^{\prime}\right)^{2}} \frac{I^{*}}{K^{*}}=\frac{1}{b \frac{I^{*}}{K^{*}}} \Rightarrow b=\frac{1}{2.25 \cdot \delta_{k}}=17.8 .
$$

The remaining parameters are functions of steady state values of the model and are determined endogenously:

The equilibrium equations 21-32 imply the following steady state relations with a recursive structure:

$$
\begin{gathered}
i^{*}=\frac{\left(1-d_{i}\right)\left(1-B z s^{*^{\alpha}}\right) f\left(n^{*}, K^{*}\right)}{1-\left(1-d_{i}\right)\left(1-B z s^{*^{\alpha}}\right)} \\
x^{*}=\delta_{k} K^{*}, \\
\omega_{K}^{*}=U^{\prime}\left(c^{*}\right), \\
q^{*}=\frac{f\left(n^{*}, K^{*}\right)}{1-\left(1-d_{i}\right)\left(1-B z s^{*^{\alpha}}\right)}, \\
\omega_{i}^{*}=\frac{v^{*} \mu\left(v^{*}\right)=\delta_{n} n^{*},}{\left(1-\beta\left(1-\delta_{i}\right)\left(1-B z s^{* \alpha}\right)\right)}, \\
s^{*^{1-\alpha}} \Phi^{\prime}\left(s^{*}\right)=z q^{*}\left[U^{\prime}\left(c^{*}\right)-\omega^{*}\right] \\
c_{b} B z s^{*^{\alpha}} \frac{f\left(n^{*}, K^{*}\right)}{1-\left(1-d_{i}\right)\left(1-B z s^{* \alpha}\right)}-\delta_{k} K^{*}, \\
U^{\prime}\left(c^{*}\right)=\left(\frac{\gamma-\beta\left(1-z s^{*^{\alpha}}\right)}{\beta z s^{* \alpha}}\right) \omega^{*}, \\
\Upsilon_{0} v^{*} / \mu\left(v^{*}\right) \frac{\left(1-\beta\left(1-\delta_{n}\right)\right)}{\sigma \beta}=\frac{B z s^{* \alpha} \omega^{*}}{\left(1-\beta\left(1-\delta_{i}\right)\left(1-B z s^{* \alpha}\right)\right)} f_{n}\left(n^{*}, K^{*}\right)-\varphi \\
U^{\prime}\left(c^{*}\right)=\frac{a_{p} f_{K}\left(n^{*}, K^{*}\right)}{1-\beta\left(1-\delta_{K}\right)} \frac{\left(1-\beta\left(1-\delta_{i}\right)\left(1-B z s^{* \alpha} \omega^{*}\right)\right)}{(43)}
\end{gathered}
$$

Equations 34 - 39 give $\left(i^{*}, x^{*}, \omega_{K}^{*}, q^{*}, v^{*}, \omega_{i}^{*}\right)$ as functions of $\left(K^{*}, c^{*}, \omega^{*}, s^{*}, n^{*}\right)$. Further, equations $40-44$ involve only $\left(K^{*}, c^{*}, \omega^{*}, s^{*}, n^{*}\right)$. 
Steady state employment $n^{*}$ is normalized to 100 . Wage bargaining determines the wage rate according to 10 :

$$
W^{*}=\sigma \frac{\varphi}{\omega^{*}}+(1-\sigma) \frac{z B s^{*^{\alpha}}}{1-\beta\left(1-\delta_{i}\right)\left(1-B z s^{* \alpha}\right)} f^{\prime}\left(n^{*}, k^{*}\right) .
$$

Using 45 and the definition of the labor income share $L I S \equiv W^{*} n^{*} / f, \varphi$ can be expressed by:

$$
\varphi=\left(\frac{L I S}{e_{f}}-\frac{(1-\sigma) z B s^{*^{\alpha}}}{1-\beta\left(1-\delta_{i}\right)\left(1-B z s^{* \alpha}\right)}\right) \frac{f^{\prime}\left(n^{*}, k^{*}\right) \omega^{*}}{\sigma} .
$$

Define further the hiring cost relative to labor cost as:

$$
H C \equiv \Upsilon_{0} v^{*^{2}} /\left(\omega^{*} W^{*} n^{*}\right) .
$$

Hence

$$
\Upsilon_{0}=\omega^{*} W^{*} n^{*} H C / v^{*^{2}}=\omega^{*} L I S f^{*} H C / v^{*^{2}},
$$

and by making use of 38

$$
k\left(v^{*}\right) \equiv \Upsilon^{\prime}\left(v^{*}\right) / \mu\left(v^{*}\right)=2 \Upsilon_{0} v^{*} / \mu\left(v^{*}\right)=2 \omega^{*} L I S f^{*} H C /\left(\delta_{n} n^{*}\right) .
$$

Substituting 46 and 49 into 43 one can solve for $e_{f}$ :

$$
e_{f}=\operatorname{LIS}\left(\beta+\frac{2 H C\left(1-\beta\left(1-\delta_{n}\right)\right)}{\delta_{n}}\right) \frac{1-\beta\left(1-\delta_{i}\right)\left(1-B z s^{* \alpha}\right)}{\beta B z s^{*^{\alpha}}} .
$$

With the hiring cost ratio set to $2 \%$ this determines $e_{f}$.

The steady state equations 41 to 42 and 44 can be used to determine the parameter $\varphi_{0}$, as well as the steady state values $K^{*}, c^{*}$ and $\omega^{*} . K^{*}$ is required to solve 44 , with $U^{\prime}\left(c^{*}\right)$ given by 42 , and $\omega^{*}$ cancels out. Plugging in the functional form of the production function one gets:

$$
\left(\frac{\gamma-\beta\left(1-z s^{*^{\alpha}}\right)}{\beta z s^{* \alpha}}\right)=\frac{a_{p}\left(1-e_{f}\right) \cdot F \cdot\left(\frac{K^{*}}{n^{*}}\right)^{-e_{f}}}{1-\beta\left(1-\delta_{K}\right)} \frac{\beta B z s^{* \alpha}}{\left(1-\beta\left(1-\delta_{i}\right)\left(1-B z s^{* \alpha}\right)\right)},
$$

which can be solved for $K^{*}$. Once $K^{*}$ is determined, $c^{*}$ follows from 41 and $\omega^{*}$ from 42 . Now $\omega_{i}^{*}$ and $q^{*}$ are given by 37 and 39 and $\varphi$ can be calculated by 46 . Finally, $\varphi_{0}$ is determined through 40 and 33 and $\Upsilon_{0}$ is given by 48 .

The resulting parameter values are shown in Table 1. 


\section{A.2 Tables}

Table 1 Parameter Values

\begin{tabular}{|c|c|c|c|c|c|c|c|c|c|c|}
\hline$\beta$ & $\gamma$ & $R A$ & $B$ & $z$ & $\delta_{n}$ & $A$ & $\sigma$ & $\psi$ & $a_{p}$ & $e_{f}$ \\
\hline 0.99 & 1.012 & 2 & 0.5263 & 0.2242 & 0.06 & 0.6 & 0.7 & 0.0447 & 0.0069 & 0.6804 \\
\hline
\end{tabular}

\begin{tabular}{|c|c|c|c|c|c|c|c|c|c|c|}
\hline$\varphi$ & $\varphi_{0}$ & $e_{\Phi}$ & $\alpha$ & $\Upsilon_{0}$ & $\delta_{i}$ & $\delta_{\mathrm{k}}$ & $\delta$ & $\rho_{s}$ & $\sigma_{s}$ & \\
\hline 0.7683 & 0.4232 & 2 & 0.8 & 0.0479 & 0.0072 & 0.025 & 17.8 & 0 & 0.01078 & \\
\hline
\end{tabular}

Table 2 Standard Deviations Relative to Output

\begin{tabular}{|c|c|c|c|c|c|c|c|}
\hline \multirow[t]{2}{*}{ Variables } & \multicolumn{4}{|c|}{ US-Data } & \multicolumn{3}{|c|}{ Simulation } \\
\hline & $\begin{array}{c}\text { Merz } \\
{[15]} \\
59 \mathrm{I}-88 \mathrm{II}\end{array}$ & $\begin{array}{l}\text { Andolfatto } \\
\text { [1] } \\
53 \text { I - } 90 \text { III }\end{array}$ & $\begin{array}{c}\text { Hornatein- } \\
\text { Sarte [9] } \\
59 \text { I - } 97 \mathrm{VV}\end{array}$ & $\begin{array}{c}\text { Khan- } \\
\text { Thomas [10] } \\
54 \text { I - } 02 \text { I }\end{array}$ & $\begin{array}{l}\text { Techn. } \\
\text { Shocka } \\
\text { only }\end{array}$ & $\begin{array}{l}\text { Techn. } \\
\& \text { Mon. } \\
\text { Shocks }\end{array}$ & $\begin{array}{c}\text { Both } \\
\text { Shockg } \\
\text { (low HC) }\end{array}$ \\
\hline Volatiditity of GDP: $\sigma_{Y}$ & $\begin{array}{l}1.87 \\
(0.05)\end{array}$ & 1.58 & 1.80 & 2.24 & $\begin{array}{r}0.88 \\
(0.08)\end{array}$ & $\begin{array}{r}0.88 \\
(0.08)\end{array}$ & $\begin{array}{l}0.84 \\
(0.07)\end{array}$ \\
\hline Consumption & $\begin{array}{l}0.40 \\
(0.03)\end{array}$ & 0.56 & 0.34 & - & $\begin{array}{l}0.59 \\
(0.02)\end{array}$ & $\begin{array}{l}0.66 \\
(0.02)\end{array}$ & $\begin{array}{l}\mathbf{0 . 6 5} \\
(0.03)\end{array}$ \\
\hline Investment & $\begin{array}{l}2.39 \\
(0.06)\end{array}$ & 3.14 & 2.07 & - & $\begin{array}{l}2.68 \\
(0.07)\end{array}$ & $\begin{array}{l}2.89 \\
(0.12)\end{array}$ & $\begin{array}{r}2.80 \\
(0.12)\end{array}$ \\
\hline Capital & $\begin{array}{l}0.22 \\
(0.03)\end{array}$ & - & - & - & $\begin{array}{l}0.25 \\
(0.10)\end{array}$ & $\begin{array}{l}0.25 \\
(0.10)\end{array}$ & $\begin{array}{c}0.24 \\
(0.11)\end{array}$ \\
\hline Final Sales & $80.0 \%$ & - & 0.81 & 0.71 & $\begin{array}{l}0.76 \\
(0.03)\end{array}$ & $\begin{array}{l}0.93 \\
(0.04)\end{array}$ & $\begin{array}{l}0.93 \\
(0.04)\end{array}$ \\
\hline Inventory Inves tment & - & - & - & 0.29 & $\begin{array}{r}\mathbf{0 . 4 8} \\
(0.03)\end{array}$ & $\begin{array}{l}0.72 \\
(0.06)\end{array}$ & $\begin{array}{l}0.77 \\
(0.06)\end{array}$ \\
\hline Inventories/Sales & - & - & - & 0.54 & $\begin{array}{l}\mathbf{0 . 5 7} \\
(0.03)\end{array}$ & $\begin{array}{l}1.01 \\
(0.11)\end{array}$ & $\begin{array}{l}1.06 \\
(0.11)\end{array}$ \\
\hline Employment & $\begin{array}{r}\mathbf{0 . 5 4} \\
(0.04)\end{array}$ & 0.67 & - & - & $\begin{array}{l}0.22 \\
(0.04)\end{array}$ & $\begin{array}{l}0.22 \\
(0.04)\end{array}$ & $\begin{array}{c}0.36 \\
(0.05)\end{array}$ \\
\hline Voseaneies & $\begin{array}{c}7.31 \\
(0.35)\end{array}$ & - & - & - & $\begin{array}{l}1.57 \\
(0.01)\end{array}$ & $\begin{array}{l}1.61 \\
(0.04)\end{array}$ & $\begin{array}{r}3.49 \\
(0.18)\end{array}$ \\
\hline
\end{tabular}

Note: Columns below the header US-Data present the standard deviation of GDP and the standard deviations of various US time series relative to GDP (See sources and data ranges in rows 2 and 3, small sample standard errors are in brackets). All series but Inventory Investment are in logarithms and detrended via HP-Filter. Inventory Investment is in levels and expressed as a ratio to GDP. Columns below the header Simulation show corresponding simulation averages over $\mathrm{N}=1000$ draws for HP-filtered artificial data of length $\mathrm{T}=200$. "Technol. Shocks only" refers to the case where only technology shocks hit the model economy, "Techn. \& Mon. Shocks" to the case where technology shocks and monetary shocks are present, "Both Shocks (low HC)" to the case with both shocks and low hiring costs: $\mathrm{HC}=0.2 \%$ of wage bill. 
Table 3 Contemporaneous Correlations with Output

\begin{tabular}{|c|c|c|c|c|c|c|}
\hline \multirow[t]{2}{*}{ Variables } & \multicolumn{3}{|c|}{ US-Data } & \multicolumn{3}{|c|}{ Simulation } \\
\hline & $\begin{array}{l}\text { Andolfat to } \\
\text { [1] } \\
53 \text { I - } 90 \text { III }\end{array}$ & $\begin{array}{c}\text { Hornatein- } \\
\text { Sarte [9] } \\
59 \text { I - } 97 \mathrm{TV}\end{array}$ & $\begin{array}{l}\text { Khan- } \\
\text { Thomas [10] } \\
54 \text { I - } 02 \text { I }\end{array}$ & $\begin{array}{c}\text { Techn. } \\
\text { Shocks } \\
\text { only }\end{array}$ & $\begin{array}{l}\text { Techn. } \\
\& \text { Mon. } \\
\text { Shocks }\end{array}$ & $\begin{array}{c}\text { Both } \\
\text { Shocka } \\
\text { (low } \mathrm{HC} \text { ) }\end{array}$ \\
\hline & \multicolumn{6}{|c|}{ Correlation with Output } \\
\hline Cons umption & 0.74 & 0.73 & - & $\begin{array}{c}\mathbf{0 . 9 2} \\
(0.01)\end{array}$ & $\begin{array}{c}\mathbf{0 . 8 1} \\
(0.03)\end{array}$ & $\begin{array}{c}\mathbf{0 . 7 8} \\
(0.04)\end{array}$ \\
\hline Investment & 0.90 & 0.68 & - & $\begin{array}{c}0.96 \\
(0.00)\end{array}$ & $\begin{array}{c}0.89 \\
(0.01)\end{array}$ & $\begin{array}{c}0.90 \\
(0.01)\end{array}$ \\
\hline Finol Sales & - & 0.94 & 0.94 & $\begin{array}{c}0.88 \\
(0.01)\end{array}$ & $\begin{array}{c}0.71 \\
(0.05)\end{array}$ & $\begin{array}{c}\mathbf{0 . 6 7} \\
(0.05)\end{array}$ \\
\hline Inventory Investment & - & - & 0.67 & $\begin{array}{c}\mathbf{0 . 6 7} \\
(0.03)\end{array}$ & $\begin{array}{c}\mathbf{0 . 4 6} \\
(0.05)\end{array}$ & $\begin{array}{c}0.47 \\
(0.05)\end{array}$ \\
\hline Inventories /Sales & - & - & -0.38 & $\begin{array}{l}-0.11 \\
(0.09)\end{array}$ & $\begin{array}{c}-0.08 \\
(0.11)\end{array}$ & $\begin{array}{c}-0.14 \\
(0.11)\end{array}$ \\
\hline \multirow[t]{2}{*}{ Employment } & 0.73 & - & - & $\begin{array}{l}-0.11 \\
(0.06)\end{array}$ & $\begin{array}{l}-0.11 \\
(0.07)\end{array}$ & $\begin{array}{c}-0.23^{\dagger} \\
(0.09)\end{array}$ \\
\hline & \multicolumn{6}{|c|}{ Correlation with Sales } \\
\hline $\begin{array}{l}\text { Inventory Investment } \\
\text { Inventories/Sales }\end{array}$ & - & $\begin{array}{l}0.27 \\
-0.59\end{array}$ & 0.41 & $\begin{array}{l}0.24 \\
(0.02) \\
0.01 \\
(0.06)\end{array}$ & $\begin{array}{c}-0.30^{\dagger} \\
(0.07) \\
-0.19 \\
(0.13)\end{array}$ & $\begin{array}{c}-0.33^{\dagger} \\
(0.06) \\
-0.06 \\
(0.11)\end{array}$ \\
\hline
\end{tabular}

Note: Columns below the header US-Data present the correlations of various US time series relative to GDP and Final Sales, respectively (See sources and data ranges in rows 2 and 3, small sample standard errors are in brackets). All series but Inventory Investment are in logarithms and detrended via HP-Filter. Inventory Investment is in levels and expressed as a ratio to GDP. Columns below the header Simulation show corresponding simulation averages over $\mathrm{N}=1000$ draws for HP-filtered artificial data of length $\mathrm{T}=200$. "Technol. Shocks only" refers to the case where only technology shocks hit the model economy, "Techn. \& Mon. Shocks" to the case where technology shocks and monetary shocks are present, "Both Shocks (low HC)" to the case with both shocks and low hiring costs: $\mathrm{HC}=0.2 \%$ of wage bill.

$\dagger$ indicates that the sign differs significantly from the corresponding one in the data. 
Table 4 Persistence of Production and Sales

\begin{tabular}{|l|cccc|cccc|}
\hline & \multicolumn{4}{|c|}{ Output } & \multicolumn{4}{c|}{ Final Sales } \\
& \multicolumn{3}{|c}{ Correlation $\left(Y_{t}, Y_{t-j}\right)$} & \multicolumn{3}{c|}{ Correlation $\left(F S_{t}, F S_{t-j}\right)$} \\
& $j=1$ & 2 & 3 & 4 & $j=1$ & 2 & 3 & 4 \\
\hline US Data & 0.72 & 0.40 & 0.10 & -0.13 & 0.72 & 0.43 & 0.14 & -0.08 \\
- Both Shocka & 0.68 & 0.42 & 0.21 & 0.06 & 0.63 & 0.39 & 0.21 & 0.08 \\
- Technology Shocks & 0.68 & 0.42 & 0.21 & 0.06 & 0.88 & 0.65 & 0.41 & 0.19 \\
\hline
\end{tabular}

Note: This table shows the autocorrelations of Output, Y, and Final Sales, FS, for 1 to 4 lags. The values corresponding to US Data are taken from Hornstein and Sarte [9].

"Both Shocks" refers to the situation where both, monetary shocks and technology shocks, hit the economy. "Technology Shocks"refers to the situation where only technology shocks are present. 


\section{A.3 Figures}

Figure 1: Role of Capital: Variation in Capital Adjustment Cost
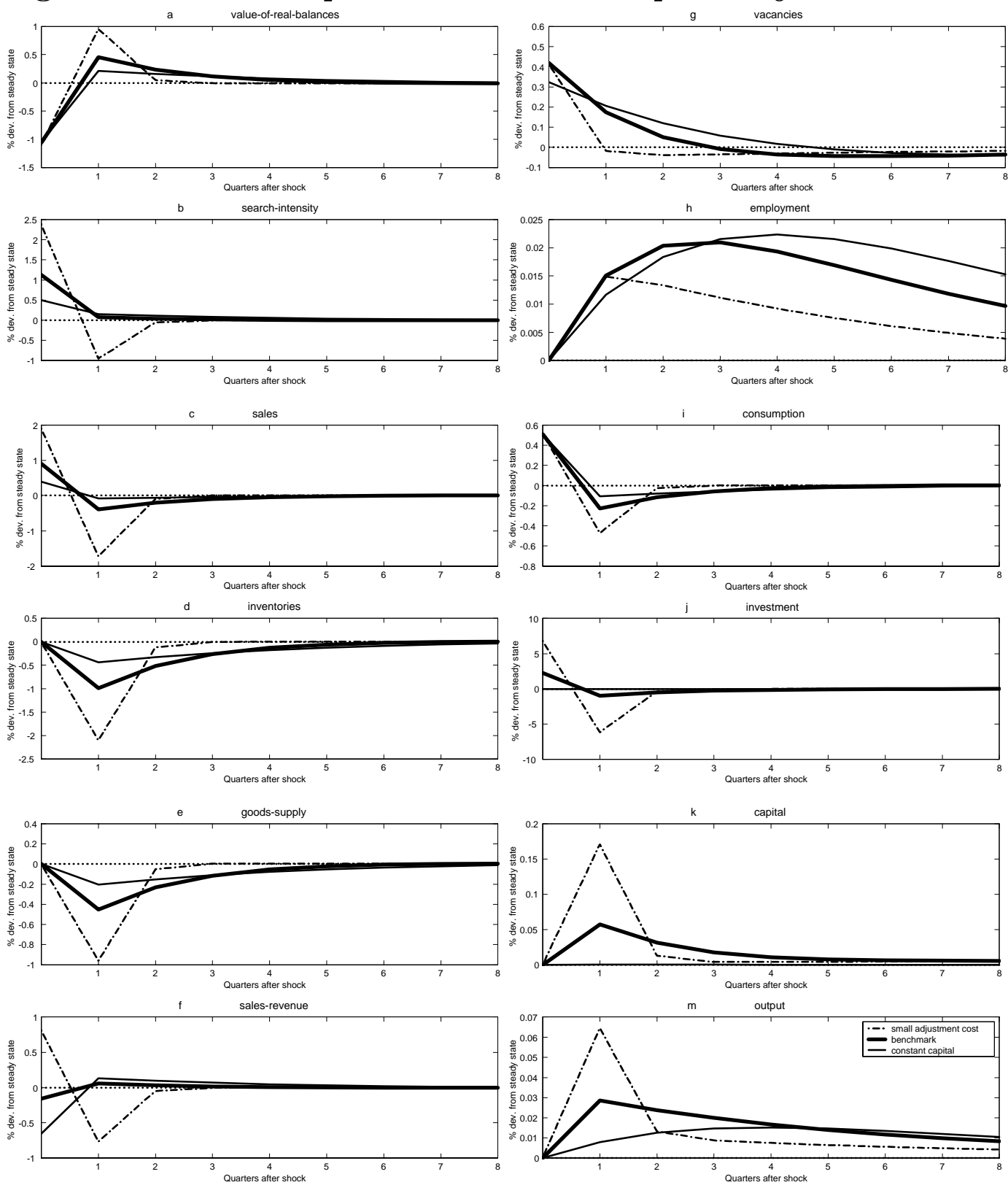

Impulse responses after a monetary shock with autocorrelation $\rho=0$. "small adjustment cost" corresponds to $b=6$, "benchmark" to $b=17.8$, and "constant capital" to $b=10000$. 
Figure 2 : Role of Inventories: High Depreciation of Inventories
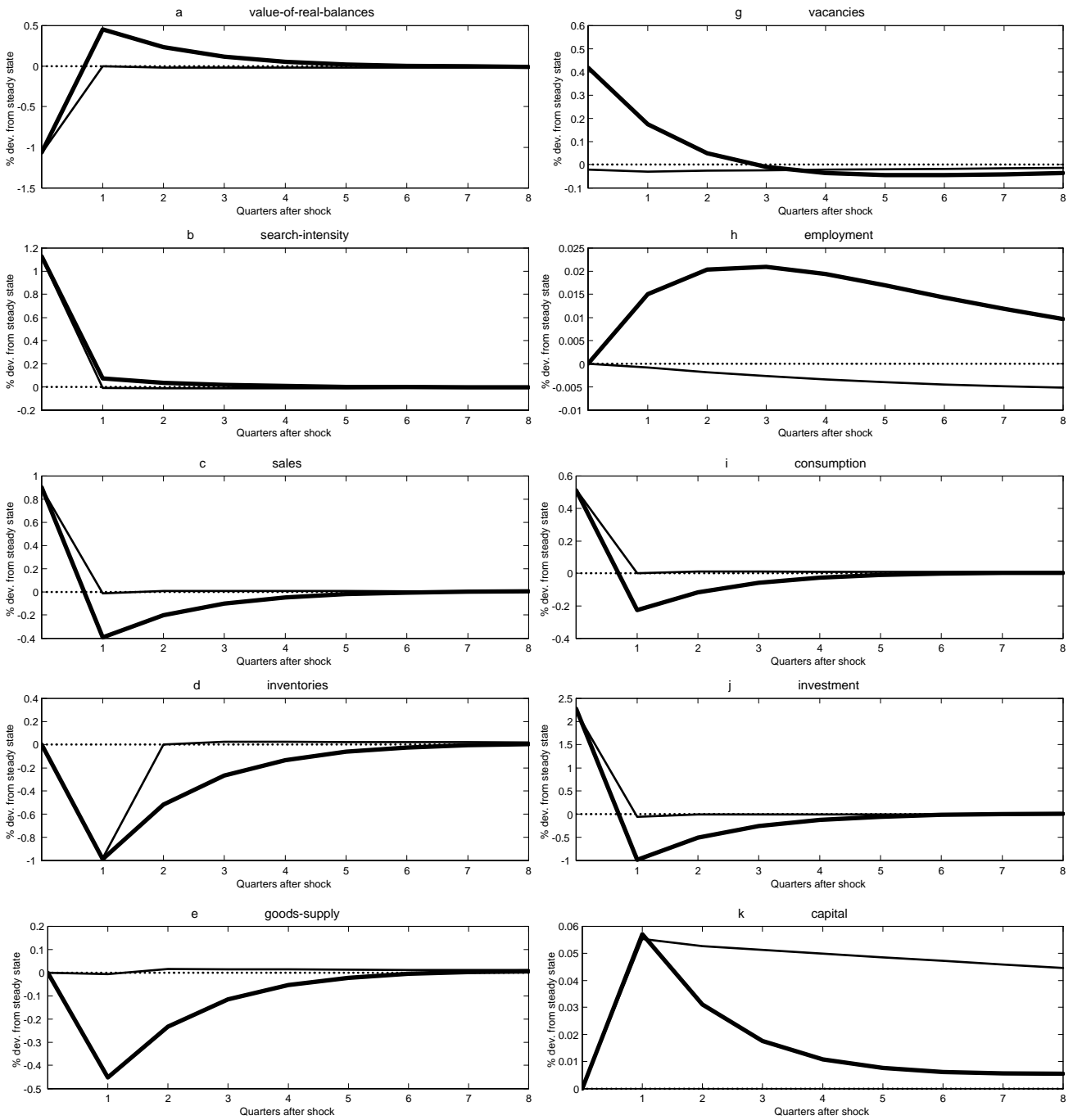

f sales-revenue
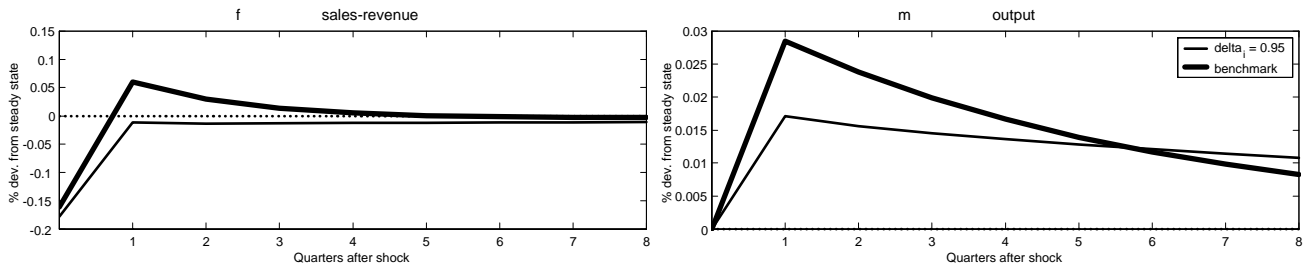

Impulse responses after a monetary shock with autocorrelation $\rho=0$. "delta $a_{i}=0.95$ " corresponds to the model where $\delta_{i}=0.95$, i.e. that only $5 \%$ of unsold goods survive as inventories to next period. "benchmark" corresponds to the benchmark model with $\delta_{i}=0.0072$. 
Figure 3 : $\quad$ CEE Monetary Policy Shock in M1
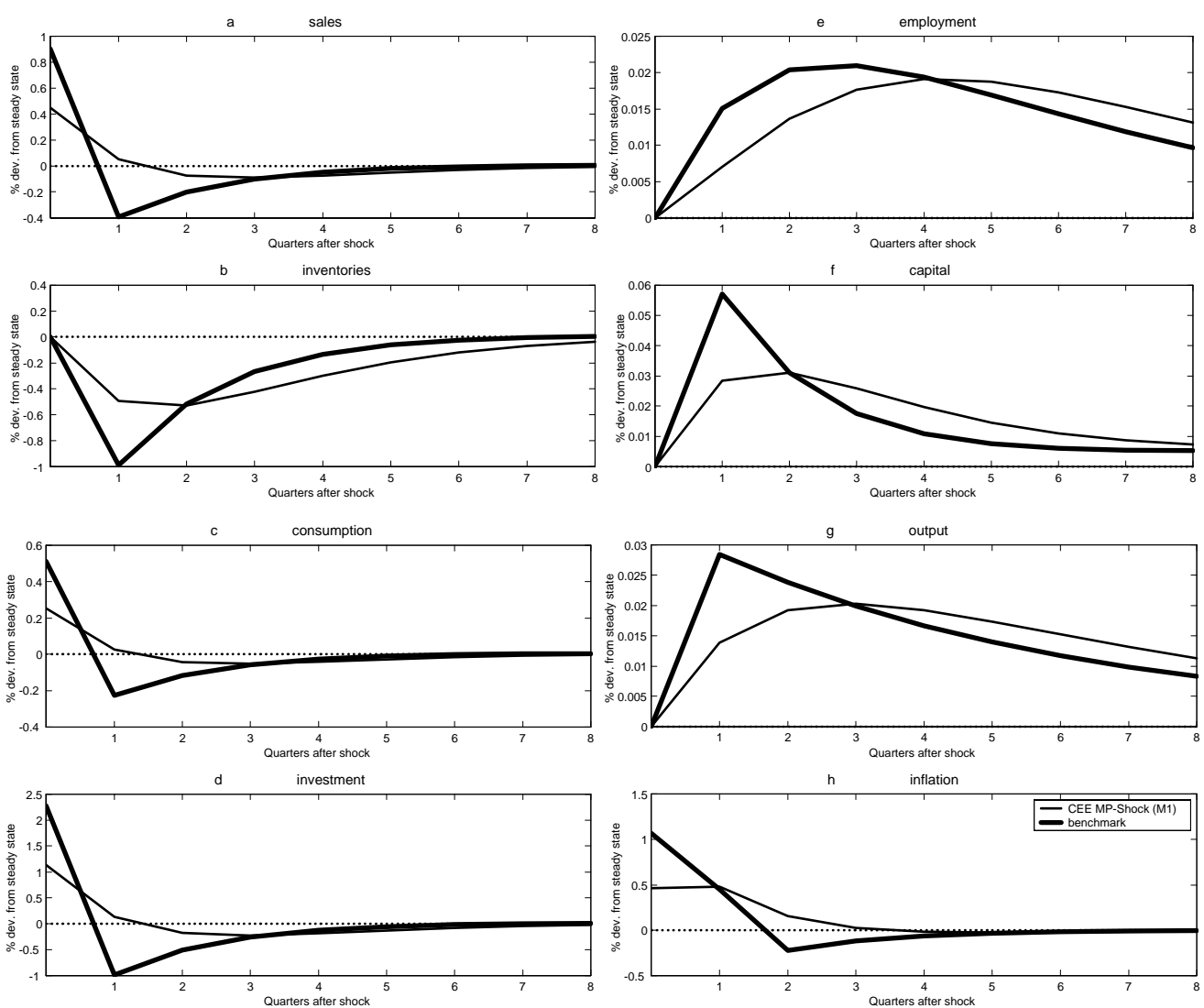

Impulse responses after a monetary policy shock in M1 with autocorrelation $\rho_{g}=0.55$ and standard deviation $\sigma_{g}=0.004716$. "benchmark" corresponds to the benchmark model with $\rho_{g}=0$ and standard deviation $\sigma_{g}=0.01078$. 
Figure 4: Technology Shock
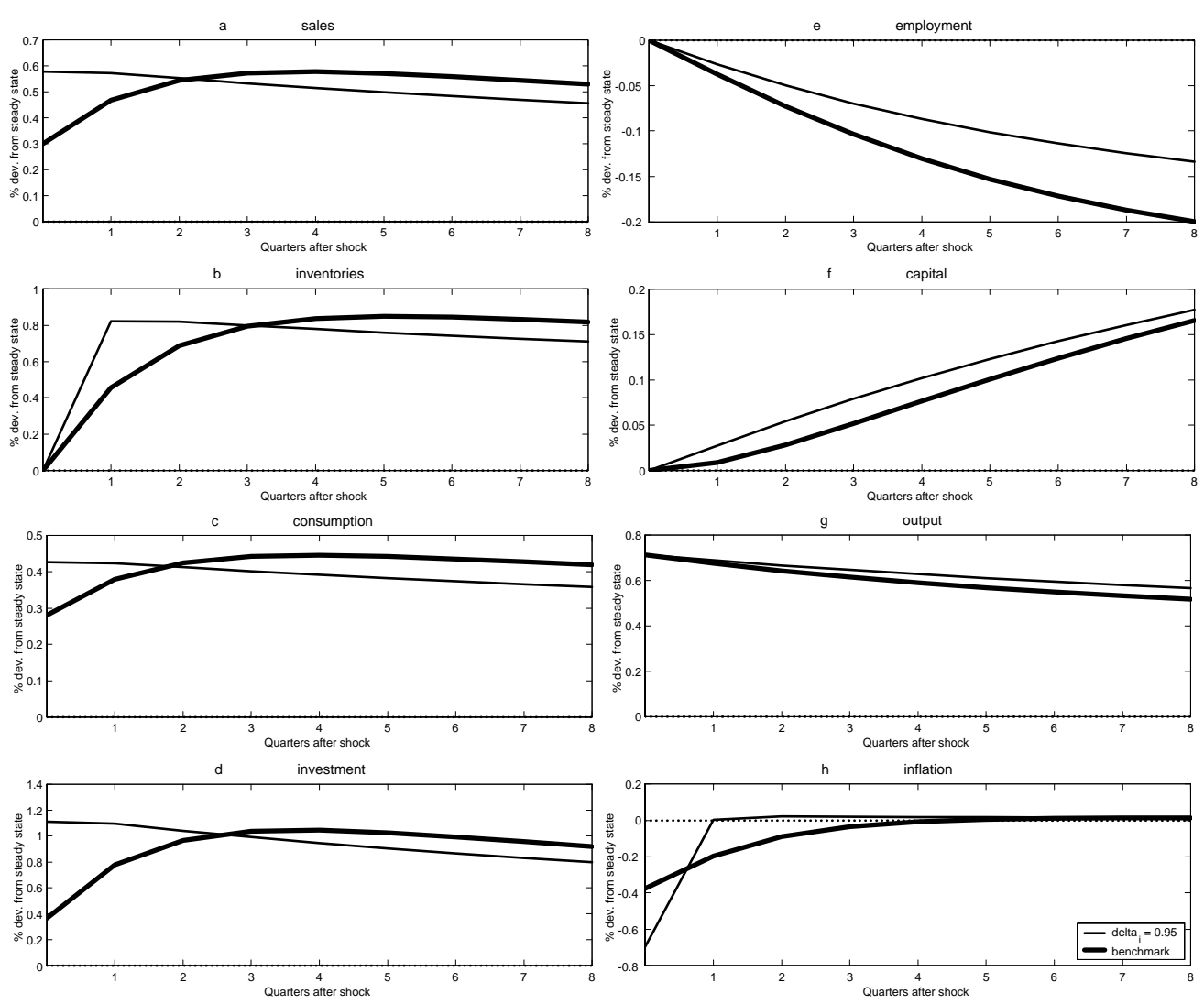

Impulse responses after a technology shock with autocorrelation $\rho_{A}=0.979$ and standard deviation $\sigma_{A}=0.00712$. "delta ${ }_{i}=0.95$ " corresponds to the model where $\delta_{i}=0.95$, i.e. that only $5 \%$ of unsold goods survive as inventories to next period. "benchmark" corresponds to the benchmark model with $\delta_{i}=0.0072$. 